\title{
THE EFFECT OF KNITTING PARAMETER AND FINISHING ON ON ELASTIC PROPERTY OF PET/PBT WARP KNITTED FABRIC
}

\author{
Qing CHEN, Pibo Ma, Haiwen Mao, Xuhong Miao, Gaoming Jiang
}

Jiangnan University, The school of textiles and clothing Lihu avenue 1800, Binhu district, Wuxi, Jiangsu, CHINA

\begin{abstract}
:
This study investigated the elastic elongation and elastic recovery of the elastic warp knittedfabric made of PET( polyethylene terephthalate) and PBT(polybutylene terephthalate) filament. Using 50/24F PET and 50D/24F PBT in two threadingbars, the tricot, locknit and satin warp knitted fabrics were produced on the E28 tricot warpknitting machine. The knitting parameters influencing the elastic elongation under $100 \mathrm{~N}$ wereanalyzed in terms of fabric structure, yarn run-in speed and drawing density set on machine.Besides, dyeing temperature and heat setting temperature/time were also examined in order toretain proper elastic elongation and elastic recovery. The relationship between elastic elongationand knitting parameter and finishing parameter were analyzed. Finally, the elastic recovery ofPET/PBT warp knitted fabric was examined to demonstrate the elastic property of final finishedfabric. This study could help us to further exploit the use of PET/PBT warp knitted fabric in thedevelopment of elastic garment in future.
\end{abstract}

\section{Keywords:}

Warp knit,elastic, PBT,elongation, recovery.

\section{Introduction}

Elastic knitted fabric was widely used in sportswear, underwear or seamless garment. Generally,elastic yarns like spandex, core-spun yarn using spandex, PU(poly urethane)/PA(Nylon), PTT(polytrimethylene-terephthalate)wereused in the platingstructure of weft knitted fabric. Pure spandex was mainly used in the production of warp knittedelastic fabric due to its smooth yarn structure. But spandex has some disadvantages such aspoordyeing property, water absorption andsun resistance. Besides, the durability and strength wasaffected by sunshine, chlorine and ageing. PBT filament had 100\% chlorine resistant.

Much research was conducted on the elastic knitted fabric using various elastic yarns. Verdu et al.compared the DOW XLA fiber of a core spun yarn with elastic PBT fiber in wovenpolyester/ cotton fabrics used for professional wear end use.[1] The effect of inlay yarn pretensionat the time of manufacturing of stretch fabrics on the pressure generated by the garmentswas studied. [2] Results show that change in inlay pre-tension significantly changes the structuralcharacteristics of the fabric, but the load elongation behavior remains unchanged up to $100 \%$ extension. Serkan et al. have studied the 44dtex spandex and $\mathrm{Ne} 30 / 1$ ring spun cotton yarnloop length value (loose, medium and tight) on the fabric weight, density, thickness, burstingstrength, air permeability of cotton/spandex half plating single jersey knitted fabrics.[3] 210Dtextured nylon yarn along with 20D covered spandex filament yarn was used as elastic inlayyarns in single jersey for the production of pressure garments.[8] Das et al. studied theinteraction effect of elastane stretch, proportion of elastane core and twist multiplier on lowstressmechanical properties of the woven fabrics made of stretchable elastanecotton core-spunyarns.[10] The physical and dimensional properties of single jersey fabrics made from cottonsheath -elastomeric core spun - were investigated.[17] The effect of stitch length, relaxation andmachine washing treatments on flexural stiffness of core spun cotton/spandex weft knittedstructures in single jersey, $1 \times 1$ rib and interlock under were studied.[15]

The plating elastic weft knitted fabrics were widely investigated. Zhou et al. studied the fullplating elastic XLA(30D and 40D)/ Coolmax (75D/72f) single jersey knitted fabric.[4] Wang etal. examined the dynamic pressure attenuation of elastic knitted plain and rib fabric in differentplating ratio of spandex (2.22 tex).[5] Zhao et al. developed the plating single jersey seamlessgarments using the $50 \mathrm{D}$ polytrimethylene terephthalate (PTT)/polyester (PET) bi-componentfilament. When compared with polyurethane (PU)/polyamide (PA) core-spun yarn (20/30D), ithad better extensibility and elastic recovery property.[6] Manshahia et al. studied the effect offilament shape factor and fabric constructional parameters on thermophysiological comfort ofthe elastane-plated fabrics intended to be used in high active sportswear.[9] Gokarneshan et al.studied the 20tex polyester/spandex core air-covered high-stretch yarn that was used to producesingle-jersey fabrics with different loop length.[7] Spandex-plated cotton fabric and spandexcore cotton spun (SCCS) fabric were also investigated. [14]

Some properties related to the comfort of elastic fabric werestudied. Thermo-physiological comfortof the compression athletic wear was studied.[11] Onofrei investigated the effect 
of moisture onthe thermal comfort properties of single jersey knitted fabric made of Outlast $₫$ and PolyesterCoolmax $®$ plated with elastane (Creora®) 77 dtex.[12] Air permeability variations of core spuncotton/spandex single jersey and $1 \times 1$ rib knitting structures were studied under the relaxationtreatments.[16]

Although there were some experimental studies on spandex weft knitted fabric, little work hasbeen done on the effect of structure, knitting parameter such as yarn run-in speed, drawingdensity set on machine, dyeing temperature, heat setting temperature and duration on elongationof PET/PBT warp knitted fabric. This paper presents a study about the warp knitting parametersthat are important to the physical elastic elongation and elastic recovery of warp knit. Therelationship and significance correlation analysis have been carried out.

\section{Sample}

\subsection{PBT filament}

PBT yarn[50D/24F DTY(Draw texturing yarn)]and PET yarn [50D/24FFDY (Fully Drawn Yarn)]were used in this study. They weresupplied by Sinopec Yizheng Chemical FibreCompany Limited in China. Table 1 lists the physical specification of PBT and PET yarn(tested by YG063T Changling ${ }^{\circledR}$ ).

\subsection{Knitting}

E28 tricot warp knitting machine was used to knit the PET/PBT fabric. Orthogonal experiment was designed to examine the three5factors such as the knitting structure, material arrangement and drawing density set on machineon the elasticity properties and three levels for each factor. The three levels of drawing density set onmachine were12, 16 and 20 CPC (course per centimeter). The three structures weretricot, locknit andsatin. The material PBT filament was arranged for GB1, GB2 or both GB1 and GB2. Table2summarizes the details of orthogonal experiment. Table 3 shows the orthogonal array of 9experiments.

\section{The effect of drawing density set on machine on elastic elongation under $100 \mathrm{~N}$}

After the orthogonal experiment, suitable knitting structure and yarn arrangement (locknitstructure; GB1 is PET, GB2 is PBT) were determined to further study the effect of knittingparameter on elastic elongation. Six different drawing densities set on machine $(16,18,20,22,24$ and $26 \mathrm{CPC})$ were selected to examine its effect on the elastic elongation under $100 \mathrm{~N}$. Consequently, the yarn run-in speed were varied according to the drawing density set,whilekeeping the yarn tension at 3-6.3 $\mathrm{cN}$. The corresponding yarn run-in speed of GB1 and GB2 islisted in Table 4.

Table 1. The physical specification of PBT yarn

\begin{tabular}{|c|c|c|c|c|c|c|}
\hline & Count & $\begin{array}{c}\text { Filament } \\
\text { number }\end{array}$ & $\begin{array}{c}\text { Breakage } \\
\text { tension } \\
\text { (cN/Tex) }\end{array}$ & $\begin{array}{c}\text { Initial } \\
\text { modulus } \\
\text { (cN/Tex) }\end{array}$ & $\begin{array}{c}\text { Elongation at } \\
\text { breakage } \\
\text { (\%) }\end{array}$ & $\begin{array}{c}\text { Boiling water } \\
\text { shrinkage } \\
(\%)\end{array}$ \\
\hline PBT & $50 \mathrm{D}$ & 24 & 30.2 & 123.1 & 26.9 & 20.1 \\
\hline PET & 50D & 24 & 33 & 36.6 & 10.8 & 3 \\
\hline
\end{tabular}

Table 2. Factors and levels included in fractional factorial design of experiment

\begin{tabular}{|c|c|c|c|c|}
\hline Level/Factor & $\begin{array}{c}\text { Factor A } \\
\text { Drawing density }\end{array}$ & \multicolumn{2}{|c|}{$\begin{array}{l}\text { Factor B } \\
\text { Structure }\end{array}$} & $\begin{array}{c}\text { Factor } \mathrm{C} \\
\text { Material arrangement }\end{array}$ \\
\hline \multirow[t]{2}{*}{ Level 1} & \multirow[t]{2}{*}{12} & & & \multirow[t]{2}{*}{$\begin{array}{l}\text { GB1-PET } \\
\text { GB2-PBT }\end{array}$} \\
\hline & & GB1:1-0/1-2// & GB2:1-2/1-0// & \\
\hline \multirow[t]{2}{*}{ Level 2} & \multirow[t]{2}{*}{16} & & & \multirow[t]{2}{*}{$\begin{array}{l}\text { GB1-PBT } \\
\text { GB2- PBT }\end{array}$} \\
\hline & & GB1:1-0/2-3// & GB2:1-2/1-0// & \\
\hline \multirow[t]{2}{*}{ Level 3} & \multirow[t]{2}{*}{20} & & & \multirow[t]{2}{*}{$\begin{array}{l}\text { GB1-PBT } \\
\text { GB2- PET }\end{array}$} \\
\hline & & GB1: $1-0 / 3-4 / /$ & GB2: 1-2/1-0// & \\
\hline
\end{tabular}


Table 3. The orthogonal array of 9 experiments

\begin{tabular}{|c|c|c|c|}
\hline $\begin{array}{c}\text { Sample } \\
\text { No }\end{array}$ & A & B & C \\
\hline 1 & 1 & 1 & 1 \\
\hline 2 & 1 & 2 & 2 \\
\hline 3 & 1 & 3 & 3 \\
\hline 4 & 2 & 1 & 2 \\
\hline 5 & 2 & 2 & 3 \\
\hline 6 & 2 & 3 & 1 \\
\hline 7 & 3 & 1 & 3 \\
\hline 8 & 3 & 2 & 2 \\
\hline 9 & 3 & 3 & 1 \\
\hline
\end{tabular}

The fabric loop density at weft and warp directions and weight after the hot water washing areshown in Table 4. When the drawing density set on machine increased from 16-26 CPC, thewashed fabric density increased dramatically at warp direction from 26 to $35 \mathrm{CPC}$, but notsignificantly at weft direction rangingfrom 19-20 CPC. The knitted fabric density has a greater impacton shrinking characteristics after the knitting process.[18] The increase of drawing density set onmachine results in the increase of fabric weight ranged from $175-192 \mathrm{~g} / \mathrm{m}^{2}$ gradually.
The effect of yarn run-in speed on elastic elongation under $100 \mathrm{~N}$

After the examination of drawing density on machine, the fabrics knitted at 18-20 CPC onmachine obtained the highest elongation. Hence, different yarn run-in speed was testedunder fabrics produced at $20 \mathrm{CPC}$ on machine. When keeping GB1(front threading bar) at $1320 \mathrm{~mm} / \mathrm{rack}$ or $1360 \mathrm{~mm} / \mathrm{rack}$, the GB2(back threading bar) varied at 1120,1170 and 1220 $\mathrm{mm} / \mathrm{rack}$. When keeping GB2 $1120 \mathrm{~mm} / \mathrm{rack}$, the GB1 varied at 1320, 1360and 1400mm/rack. As shown in Table 5, an increase indraw-ratio of elastic yarn led to an increaseinstitch density and fabric weight.[19]

\section{Dyeing}

In order to examine the effect of dyeing temperature on the elastic elongation of fabric, threedyeing temperatures $\left(130^{\circ} \mathrm{C}\right.$, $135^{\circ} \mathrm{C}$ and $140^{\circ} \mathrm{C}$ for $30 \mathrm{~min}$ ) were selected to treat the PET/ PBTwarp knitted fabric. LA2002A IR dyeing machine (Rapid ${ }^{\circledR}$ ) was used to conduct the dyeing process. The detailed ingredients were disperse dye (1\%), high temperature leveling agent $(3 \mathrm{ml} / \mathrm{l})$, dispersing agent $(1 \mathrm{ml} / \mathrm{l})$. Bath ratio is $1: 10$.

Dye process (as shown in Figure 1):

1. From $20^{\circ} \mathrm{C}$ to $90^{\circ} \mathrm{C}$ for $15 \mathrm{~min}$

2. From $90^{\circ} \mathrm{C}$ to $120^{\circ} \mathrm{C}$ for $30 \mathrm{~min}$

Table 4. Different CPC on machine, yarn run-in speed, yarn tension and fabric density, weight after hot water washing

\begin{tabular}{|c|c|c|c|c|c|c|c|}
\hline \multirow{2}{*}{$\begin{array}{l}\text { Course per } \\
\text { centimeter } \\
\text { on machine } \\
(\text { loop/cm) }\end{array}$} & \multicolumn{2}{|c|}{$\begin{array}{l}\text { Yarn feeding speed } \\
\text { (mm/rack) }\end{array}$} & \multicolumn{2}{|c|}{$\begin{array}{l}\text { Yarn tension on } \\
\text { machine } \\
\text { (cN) }\end{array}$} & \multicolumn{2}{|c|}{$\begin{array}{l}\text { Density(after washing) } \\
\text { (loop/cm) }\end{array}$} & \multirow{2}{*}{$\begin{array}{c}\text { Weight }\left(\mathrm{g} / \mathrm{m}^{2}\right) \\
\text { (after washing) }\end{array}$} \\
\hline & GB1 & GB2 & GB1 & GB2 & CPC & WPC & \\
\hline 16 & 1430 & 1300 & 4.8 & 3.5 & 19 & 26 & 175 \\
\hline 18 & 1390 & 1250 & 3.8 & 3 & 19 & 28 & 177 \\
\hline 20 & 1360 & 1170 & 4.7 & 3 & 20 & 30 & 178 \\
\hline 22 & 1320 & 1120 & 5.2 & 4 & 19 & 32 & 180 \\
\hline 24 & 1280 & 1080 & 5.8 & 5 & 20 & 34 & 185 \\
\hline 26 & 1260 & 1060 & 6.3 & 5 & 20 & 35 & 192 \\
\hline
\end{tabular}

Table 5. Fabrics knitted at $20 \mathrm{CPC}$ on machine, yarn run-in speed, yarn tension and fabric density, weight after washing

\begin{tabular}{|c|c|c|c|c|c|c|c|}
\hline $\begin{array}{c}\text { Course per } \\
\text { centimeter } \\
\text { on machine } \\
\text { (loop/cm) }\end{array}$ & \multicolumn{2}{|c|}{$\begin{array}{c}\text { Yarn feeding speed } \\
\text { (mm/rack) }\end{array}$} & \multicolumn{2}{|c|}{$\begin{array}{c}\text { Yarn tension on } \\
\text { machine } \\
\text { (cN) }\end{array}$} & \multicolumn{2}{c|}{$\begin{array}{c}\text { Density(after washing) } \\
\text { (loop/cm) }\end{array}$} & $\begin{array}{c}\text { Weight(g/m }{ }^{2} \text { ) } \\
\text { (after washing) }\end{array}$ \\
\cline { 2 - 8 } & GB1 & GB2 & GB1 & GB2 & CPC & WPC \\
\hline 20 & 1320 & 1120 & 7.8 & 4.7 & 21 & 30 & 192 \\
\hline 20 & 1320 & 1170 & 5.5 & 2.5 & 19 & 31 & 183 \\
\hline 20 & 1320 & 1220 & 4.5 & 0 & 19 & 32 & 181 \\
\hline 20 & 1360 & 1120 & 6 & 4.5 & 21 & 30 & 182 \\
\hline 20 & 1360 & 1170 & 4.7 & 3 & 20 & 30 & 178 \\
\hline 20 & 1360 & 1220 & 3 & 2 & 21 & 29 & 176 \\
\hline
\end{tabular}


3. From $125^{\circ} \mathrm{C}$ to $130^{\circ} \mathrm{C} / 135^{\circ} \mathrm{C} / 140^{\circ} \mathrm{C}$ for $15 \mathrm{~min}$

4. Retain $130^{\circ} \mathrm{C} / 135^{\circ} \mathrm{C} / 140^{\circ} \mathrm{C}$ for $30 \mathrm{~min}$

5. From $130^{\circ} \mathrm{C} / 135^{\circ} \mathrm{C} / 140^{\circ} \mathrm{C}$ to $80^{\circ} \mathrm{C}$ for $30 \mathrm{~min}$

After that, the fabric should be washed with $\mathrm{NaOH}(2 \mathrm{~g} / \mathrm{L})$ at $80^{\circ} \mathrm{C}$ for $10 \mathrm{~min}$ at $1: 30$.

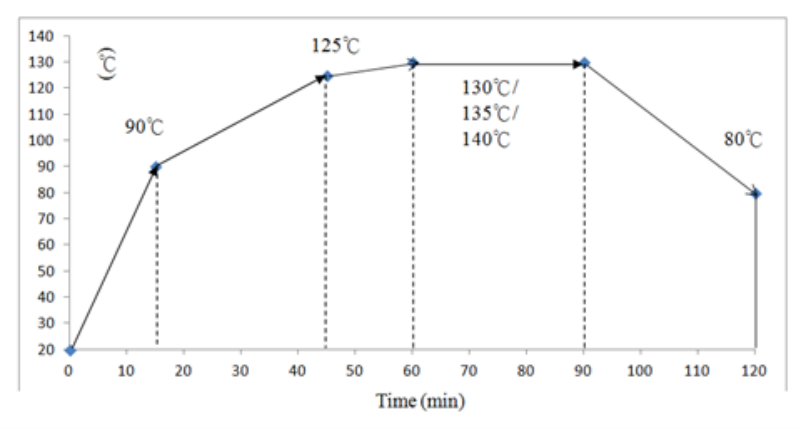

Figure 1. Dyeing process

\section{Heat setting}

The four levels of temperature and three levels of duration time of heat setting were selected totreat fabrics. The continuous dryerMini-Tenter ( Rapid $^{\circledR}$ ) was used to conduct the heat setting process. The temperatures are $145^{\circ} \mathrm{C}, 155^{\circ} \mathrm{C}, 165^{\circ} \mathrm{C}$ and $175^{\circ} \mathrm{C}$, while the duration times are $40 \mathrm{~s}, 45$ sand $50 \mathrm{~s}$.

\subsection{Test}

According to Chinese standard FZ/T 70006(stretch and recovery testing method for knits), aconstant-rate-of-extension (CRE) type tensile testing machine(YG026C, Changyi Fangyi ${ }^{\circledR}$ ) was used to measure the fabricelastic elongation under certain tension and elastic recovery at certain percent elongation atrepeated cycle testing. The specimen is $200 \mathrm{~mm} * 50 \mathrm{~mm}$ (length* width). The testing distance is $100 \mathrm{~mm}$ at length and $50 \mathrm{~mm}$ at width.

\section{The elongation under $100 \mathrm{~N}$}

The testing condition of elongation under $100 \mathrm{~N}$ tension is listed in Table 6 . The specimen wasextended at $100 \mathrm{~mm} / \mathrm{min}$ speed, and returned at $100 \mathrm{~mm} / \mathrm{min}$ speed to zero tension. The elongationof fabric wasrecorded by the tester. The fabric was given $1 \mathrm{~N}$ pre-load. Every specimen was tested 3times for the calculation of average at both weft and warp directions.

\section{The elastic recovery property}

Since human body movement expands the skin by 10 to $50 \%$ at different parts,[22] the elasticrecovery at $10 \%, 30 \%$ and $50 \%$ extensions at 1, 3, 5 cycles were measured. The fabric was stretched to $10 \%$ extension at $100 \mathrm{~mm} / \mathrm{min}$ speed, and was held at this extension for $1 \mathrm{~min}$, and then thetension was unloaded at $100 \mathrm{~mm} / \mathrm{min}$ to the original position for $3 \mathrm{~min}$ relaxation, and after that the fabric wasreloaded $1 \mathrm{~N}$ to measure the length of elongation. The whole process for $10 \%$ extension for 1 cycle is presented above. Additionally, the testing cycle was repeated for 3 and 5 cycles separatelyfor $10 \%$ extension. 30\% and $50 \%$ extensions for 1 cycle, 3 cycles and 5 cycles stretch were testedusingthe same process. The final elongation and percentage of elastic recovery wererecorded corresponding to $10 \%, 30 \%$ and $50 \%$ extensions. Every specimen was tested 3 times for calculation of averageat both weft and warp direction. The testing parameters are listed in Table 7 . Theequation of elastic recovery is demonstrated in Eq 1.

The elastic recovery $(\%)=\frac{L_{01}-L_{0}{ }^{\prime}}{L_{01}-L_{0}} \times 100 \%(\mathrm{Eq} 1)$

$\mathrm{L}_{0}$-fabric length when loaded pre-tension $(\mathrm{mm})$

$\mathrm{L}_{0}$ '-fabric length after test when loaded pre-tension $(\mathrm{mm})$

$\mathrm{L}_{01}-$ fabric length*${ }^{*}(1+$ percentage of extension) $(\mathrm{mm})$

Table 6. The elongation testing condition

\begin{tabular}{|c|c|c|c|c|c|}
\hline Fabric width & Testing distance & Loading speed & Unloading speed & Pre-tension & Tension \\
\hline $50 \mathrm{~mm}$ & $100 \mathrm{~mm}$ & $100 \mathrm{~mm} / \mathrm{min}$ & $100 \mathrm{~mm} / \mathrm{min}$ & $1 \mathrm{~N}$ & $100 \mathrm{~N}$ \\
\hline
\end{tabular}

Table 7. The elastic recovery testing condition

\begin{tabular}{|c|c|}
\hline Item & Setting parameter \\
\hline Extension percentage & $10 \%, 30 \%, 50 \%$ \\
\hline Fabric width & $50 \mathrm{~mm}$ \\
\hline Testing length & $100 \mathrm{~mm}$ \\
\hline Loading speed(unload speed) & $100 \mathrm{~mm} / \mathrm{min}$ \\
\hline Unloading speed(unload speed) & $100 \mathrm{~mm} / \mathrm{min}$ \\
\hline Repeated cycles & $1,3,5$ \\
\hline Extension time & $1 \mathrm{~min}$ \\
\hline Relaxation time & $3 \mathrm{~min}$ \\
\hline
\end{tabular}




\section{Results and discussion}

\section{The effect of knitting parameters on extension property}

The analysis of the experiment is reported in Table 8 . The $R$ value indicates that the level of influence of the three factors is $C>A>B$ for sum of warp and weft direction. The optimum extraction condition is predicted to be $\mathrm{A} 1 \mathrm{~B} 1 \mathrm{C} 2$. This is because if the fabric structure is loose, it is easy to stretchto a large extent. PBT was used in two needle bars for factor $C$ at level 2; the high stretchability is highest due to the presence of $100 \%$ PBT. Locknit (factor B at level 2) was determined to be a better structure to knit elastic fabric.

Table 8. The values of extracted and range analysis for the orthogonal array of 9 experiments

\begin{tabular}{|c|c|c|c|c|}
\hline \multirow{2}{*}{$\begin{array}{l}\text { Sample } \\
\text { No }\end{array}$} & \multirow[t]{2}{*}{ A } & \multirow[t]{2}{*}{ B } & \multirow[t]{2}{*}{ C } & $\begin{array}{l}\text { Elongation } \\
\text { under } 100 \mathrm{~N}\end{array}$ \\
\hline & & & & (Warp+Weft) \\
\hline 1 & 1 & 1 & 1 & 386.33 \\
\hline 2 & 1 & 2 & 2 & 413.03 \\
\hline 3 & 1 & 3 & 3 & 258.6 \\
\hline 4 & 2 & 1 & 2 & 401.1 \\
\hline 5 & 2 & 2 & 3 & 260.93 \\
\hline 6 & 2 & 3 & 1 & 226.47 \\
\hline 7 & 3 & 1 & 3 & 207.5 \\
\hline 8 & 3 & 2 & 2 & 222.34 \\
\hline 9 & 3 & 3 & 1 & 275.57 \\
\hline K1 & 1057.96 & 994.93 & 835.14 & \\
\hline $\mathrm{K} 2$ & 888.50 & 896.30 & 1089.70 & \\
\hline $\mathrm{K} 3$ & 705.41 & 760.64 & 727.03 & \\
\hline k1 & 352.65 & 331.64 & 278.38 & \\
\hline k2 & 296.17 & 298.77 & 363.23 & \\
\hline k3 & 235.14 & 253.55 & 242.34 & \\
\hline $\mathrm{R}$ & 117.52 & 78.10 & 120.89 & \\
\hline
\end{tabular}

The effect of drawing density on elastic elongation under $100 \mathrm{~N}$

Figure 2 illustrates the increase of drawing density on machine (CPC) results in the decrease ofelongation at weft direction. When density varied from 16 to $18 \mathrm{CPC}$, the elongation at weftdirection was larger than that at warp direction. When density increased from 20 to $26 \mathrm{CPC}$, thereverse trend was found. Furthermore, the decrease at weft direction was much larger than the increase at warp direction.

When the drawing density set on machine was $16 \mathrm{CPC}$, the elongation reached the highest value at $131.62 \mathrm{~cm}$ at weft direction, while there was $102.75 \mathrm{~cm}$ at warp direction. In general, the balancepoint of elongation between weft and warp direction was found at 18 or $20 \mathrm{CPC}$ for drawingdensity set on machine. Consequently, the drawing density set on machine can be selected from 18 to $20 \mathrm{CPC}$ on E28 tricot machine.

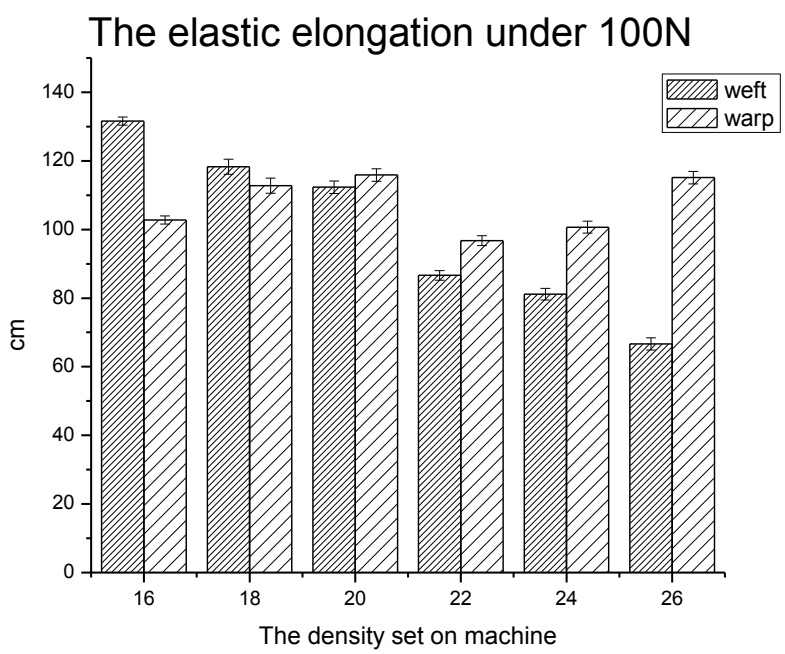

Figure 2. The fabric elongation under different $\mathrm{CPC}$ on machine

The linear regression is given in Table 9. The relationship between elongation in weft directionand density set on machine is negatively, highly and significantly related ( $\mathrm{Y} 1=$ $\left.-6.5967 X+37.97, R^{2}=0.9737, P=0.000\right)$. The elongation in weft direction linearly decreased as the densityincreased. But there is no relationship between elongations in warp direction $\left(R^{2}=0.0018\right)$.

\section{The effect of yarn run-in speed on elastic elongation under $100 \mathrm{~N}$}

After the examination of drawing density on machine, at18-20 loop/cm densities on machine, relatively balanced elongation was obtained at both weft and warp direction. Hence,different

Table 9. The relationship between elongations in weft /warp direction and CPC on machine

\begin{tabular}{|c|c|c|c|}
\hline & Regression equation & $\mathbf{R}^{2}$ & significance \\
\hline$Y_{1}$ :elongation in weft direction & $Y_{1}=-6.5967 x+237.97$ & 0.9737 & $P=0.000<0.05$ \\
\hline$Y_{2}$ :elongation in warp direction & $Y_{2}=0.0934 x+105.36$ & 0.0018 & $P=0.0936>0.05$ \\
\hline
\end{tabular}

Note: $x$-density(CPC) set on machine 
yarn run-in speeds were tested under 20 CPC (course per centimeter) on machine. The yarn run-in speed of GB1 (front threading bar) and GB2 (back threading bar) varied to examineits effect on the elastic elongation of fabric under constant density (CPC).

When keeping the yarn run-in speed of GB1 at $1320 \mathrm{~mm} /$ rack, the increase of GB2 yarn run-inspeed from 1120 to 1220 $\mathrm{rack} / \mathrm{mm}$ resulted in the increase of elastic elongation at warp direction.But, the elongation at weft direction did not show this trend. Warp elongation increased from $104.16 \mathrm{~cm}$ to $124.97 \mathrm{~cm}$, while weft elongation decreased from $110.34 \mathrm{~cm}$ to $98.03 \mathrm{~cm}$ (see Figure 3).The sum of elongationat weft and warp direction reached the highest value $(226.62 \mathrm{~cm})$ under $100 \mathrm{~N}$ tension.

The relationship between the elongation and the run-in speed of back threading bar has been examined in Table 10. When the front threading bar (GB1) yarn run-in speed is kept at $1320 \mathrm{~mm} /$ rack, anincrease in the yarn run-in speed of back threading bar (GB2) increased the warp elongation(Y2 $=0.2081 \mathrm{X}-131.31$, $\left.R^{2}=0.8625\right)$, but not significantly $(P=0.242>0.05)$. There was no relationship found between the run-in speed of back bar with weft elongation $\left(R^{2}=0.3337\right)$.

When the yarn run-in speed of GB1 is $1360 \mathrm{~mm} / \mathrm{rack}$, the increase of run-in speed of GB2 from $1120 \mathrm{~mm} / \mathrm{rack}, 1170$ $\mathrm{mm} / \mathrm{rack}$, to $1220 \mathrm{~mm} /$ rack decreased the elongation at weft directiondramatically, while the elongation of warp direction did not differ much (see Figure 4). The highest balanced elongation for the combination of GB1 and GB2 (1360:1170) was found with weft direction at $126.32 \mathrm{~cm}$ and warp direction at $115.88 \mathrm{~cm}$ respectively. This evidence is different when GB1 is kept at $1320 \mathrm{~mm} / \mathrm{rack}$. This may be because the yarn tension

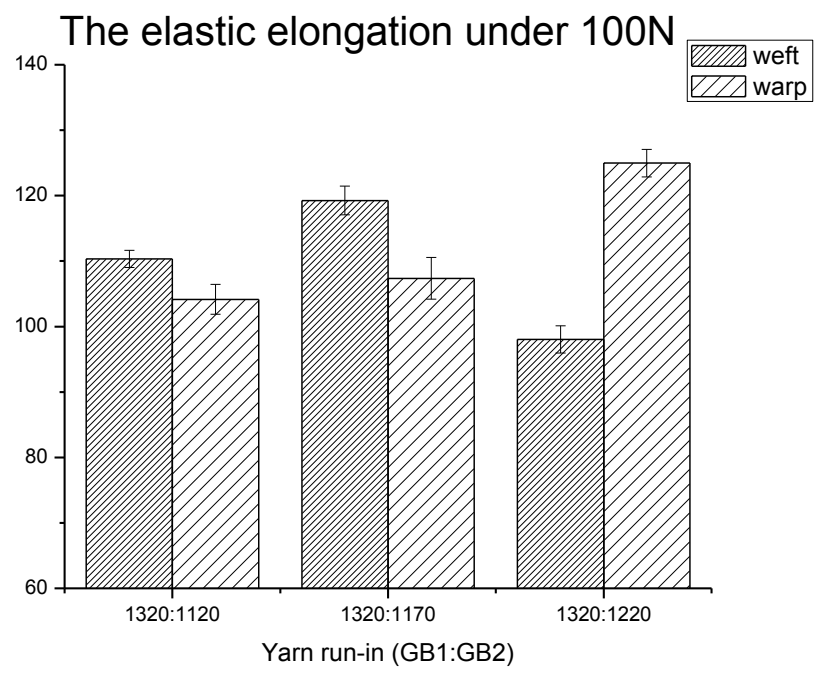

Figure 3. The fabric elongation under $1320 \mathrm{~mm} / \mathrm{rack}$ run-in speed of GB1 of GB1 and GB2 are not controlled to be exactly same when GB1 is supplying yarn at 1360 or $1320 \mathrm{~mm} /$ rack.

When keeping yarn run-in speed of front threading bar at $1360 \mathrm{~mm} / \mathrm{rack}$, the relationshipbetween run-in speed of back threading bar and weft elongation is negatively related (Y1=$\left.0.3219+493.46, R^{2}=0.7934\right)$. There is a positive relationship between yarn run-in speed of backthreading bar and warp elongation $\left(y=0.0537 x+51.654, R^{2}=0.8313\right)$. However, the linear regression is not significant, as indicted by high $P$ values in Table $11(\mathrm{P}=0.300>0.05, \mathrm{P}=0.269>0.05)$.

When keeping the yarn run-in speed of GB2 constant at1120 $\mathrm{mm} /$ rack and varying the run-in speed ofGB1 from 1320 $\mathrm{mm} / \mathrm{rack}, 1360 \mathrm{~mm} /$ rack to $1400 \mathrm{~mm} / \mathrm{rack}$, warp elongation increased from $104.16 \mathrm{~cm}$ to $124.97 \mathrm{~cm}$, while weft elongation decreased from $110.34 \mathrm{~cm}$ to $98.03 \mathrm{~cm}$. When the yarnrunin speed of GB1 and GB2 were retained at $1360 \mathrm{~mm} / \mathrm{rack}$ and $1120 \mathrm{~mm} /$ rack, it not onlybalanced the two directions of elongation but also reached the highest elongation in both directions $(128.19 \mathrm{~cm}$ and $111.1 \mathrm{~cm})$ among this group of runin speed (see Figure 5).

As listed in Table 12, the weft and warp elongation wasweakly related with the run-in speed offront threading bar due to low $R^{2}$ values ( $R^{2}=0.3034$ for weft, $R^{2}=0.4399$ for warp). Itdemonstrated that PBT yarn run-in speed constant at back threading bar will determine the elongationof PET/PBT warp knitted fabric. It is found that the weft and warp elongations were influenced more by the back threading bar than the front threading bar. It is because the PBT filamentthreaded in back bar, which is dominated by the elastic property of PET/PBT warp knitted fabrics.

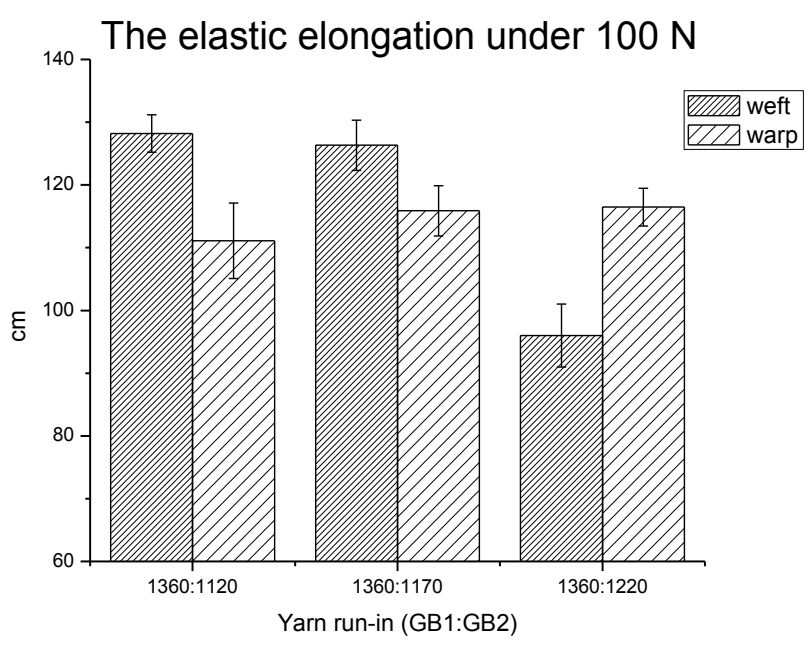

Figure 4. The fabric elongation under $1360 \mathrm{~mm} /$ rack run-in speed of GB1

Table 10. The relationship between elongations in weft /warp direction and GB2 yarn run-in speed

\begin{tabular}{|c|c|c|c|}
\hline & Regression equation & $\mathbf{R}^{2}$ & significance \\
\hline$Y_{1}$ :elongation in weft direction & $Y_{1}=-0.1231 x+253.23$ & 0.3337 & $P=0.608>0.05$ \\
\hline$Y_{2}$ :elongation in warp direction & $Y_{2}=0.2081 \mathrm{x}-131.31$ & 0.8625 & $\mathrm{P}=0.242>0.05$ \\
\hline
\end{tabular}

Note: X-the yarn run-inspeed of GB2 when yarn run-inspeed of GB1 is $1320 \mathrm{~mm} / \mathrm{rack}$ 


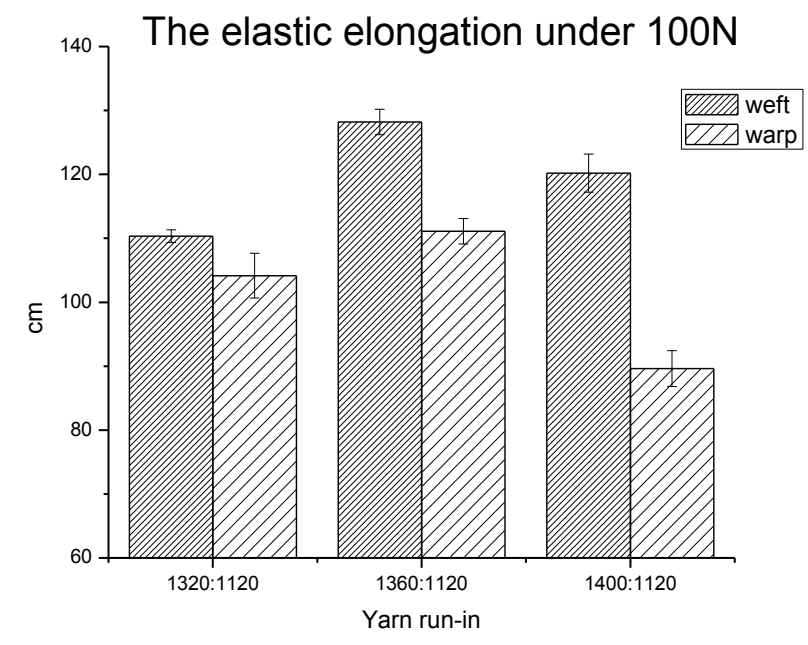

Figure 5. The fabric elongation under $1120 \mathrm{~mm} /$ rack run-in speed of GB2

The effect of dyeing temperature on elongation under $100 \mathrm{~N}$

The heat treatment temperature had an impact on proportional extensibility and shrinkage ratio of spandex.[20] The Figures 6 (a) and (b) demonstrate the elongation results of dyed fabric at $130^{\circ} \mathrm{C}, 135^{\circ} \mathrm{C}$ and $140^{\circ} \mathrm{C}$ for different drawing density on machine. It is found the fabric dyed at $140^{\circ} \mathrm{C}$ shows the lowest elongation. It means that the higher temperature will destroy the elastic elongation of the PET/PBT warp knitted fabric. Generally, the highest value was found at $130^{\circ} \mathrm{C}$ for majority of fabric density.

The relationship between drawing density and temperature and elongation was negatively correlated (see Table 13). The higher fabric drawing density and higher dyeing temperature canbe associated with elongation.

\section{The effect of dyeing temperature on elastic recovery}

The higher temperature also impacts the elastic recovery of PET/PBT warp knitted fabric. As shown in Figures 7 (a) and (b), the fabric treated at $130^{\circ} \mathrm{C}$ mainly had higher elastic recovery test edunder $30 \%$ extension for 3 cycles stretch, for majority of densities expected at 16 CPC. It is because the fabric at 16 CPC had a much looser structure andhigher temperature caused highfabric shrinkage. As the treatment temperature increased, the extensibility increased proportionally to the standard length of sample and the shrinkage ratio in the direction of course and

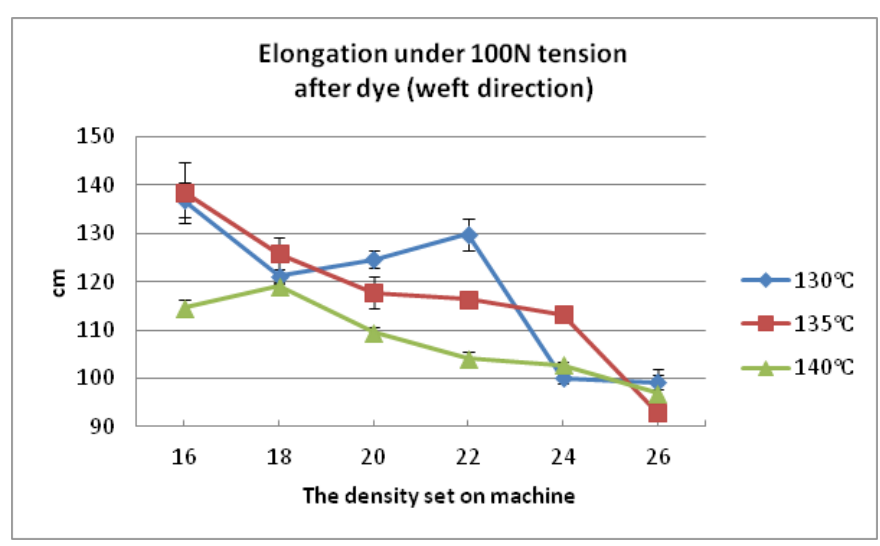

(a)

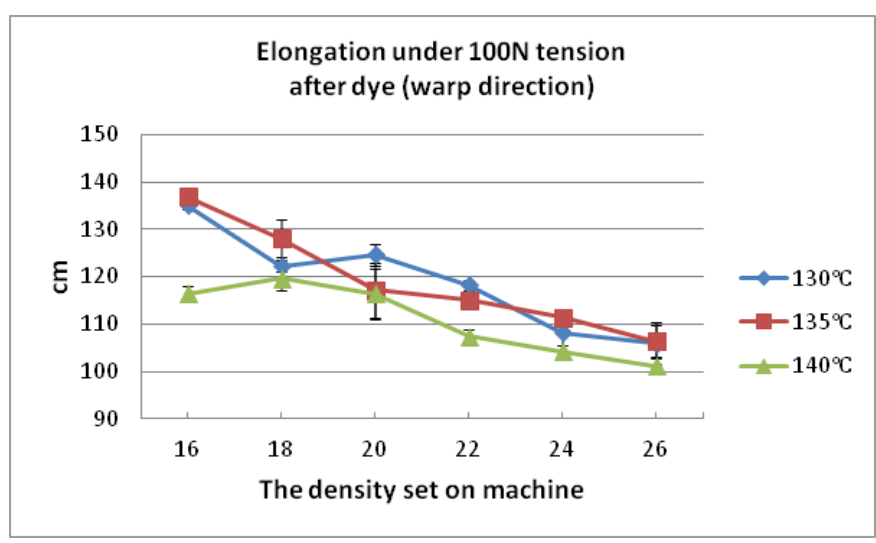

(b)

Figure 6. The fabric elongation under different dyeing temperature for 16-26 CPC

Table 11. The relationship between elongations in weft /warp direction and GB2 yarn run-in speed

\begin{tabular}{|c|l|c|c|}
\hline & Regression equation & $\mathbf{R}^{2}$ & significance \\
\hline$Y_{1}$ :elongation in weft direction & $Y_{1}=-0.3219 x+493.46$ & 0.7934 & $P=0.300>0.05$ \\
\hline$Y_{2}$ :elongation in warp direction & $Y_{2}=0.0537 x+51.654$ & 0.8313 & $P=0.269>0.05$ \\
\hline
\end{tabular}

Note: $x$-the yarn feeding speed of GB2 when yarn feeding speed of GB1 is $1360 \mathrm{~mm} / \mathrm{rack}$

Table 12. The relationship between elongations in weft /warp direction and GB1 yarn run-in speed

\begin{tabular}{|c|c|c|c|}
\hline & Regression equation & $\mathbf{R}^{\mathbf{2}}$ & significance \\
\hline$Y_{1}$ :elongation in weft direction & $Y_{1}=0.1231 x-47.877$ & 0.3034 & $P=0.629>0.05$ \\
\hline$Y_{2}$ :elongation in warp direction & $Y_{2}=-0.1818 x+348.81$ & 0.4399 & $P=0.538>0.05$ \\
\hline
\end{tabular}

Note: $x$-the yarn feeding speed of GB1 when yarn feeding speed of GB2 is $1120 \mathrm{~mm} / \mathrm{rack}$

Table 13. The relationship between the elongation and dyeing temperature and density set on machine

\begin{tabular}{|c|c|c|c|}
\hline & Regression equation & $\mathbf{R}^{2}$ & significance \\
\hline$Y_{1}$ :elongation in weft direction & $Y_{1}=-3.124 X 1-1.079 X 2+325.923$ & 0.772 & 0.000 \\
\hline$Y_{2}$ :elongation in warp direction & $Y_{2}=-2.523 X 1-0.813 X 2+279.155$ & 0.862 & 0.000 \\
\hline
\end{tabular}


wale increased.[20] The fabric structure will become dense, and then the elastic recovery will increase within certain range.

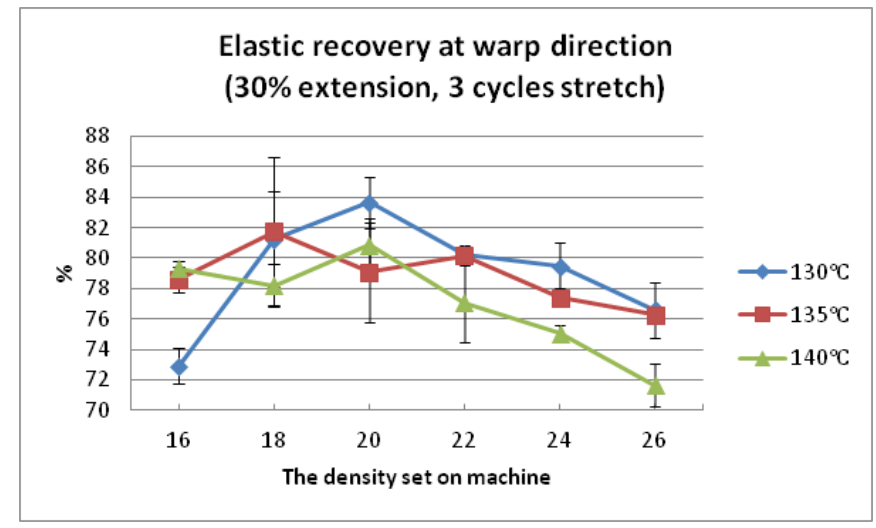

(a)

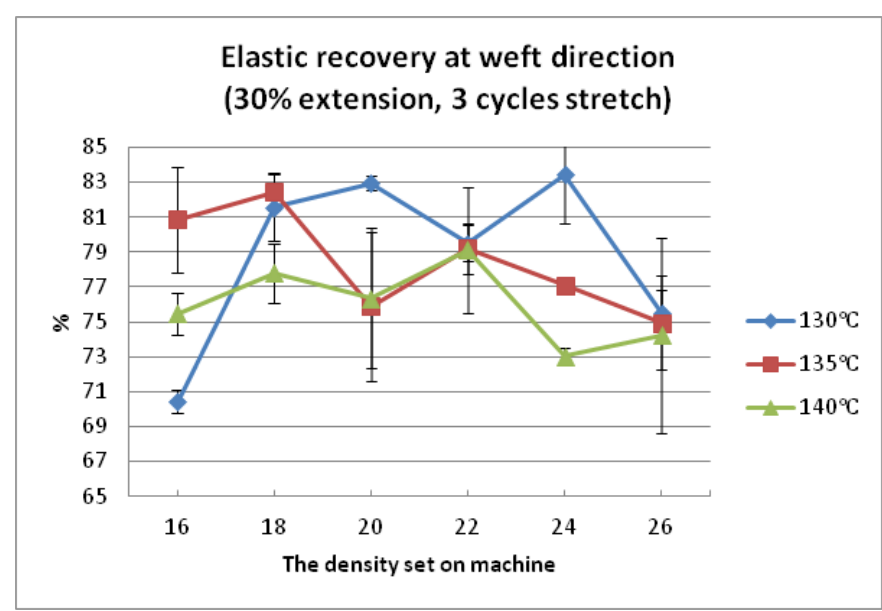

(b)

Figure 7. The elastic recovery under $30 \%$ extension for 3 cycles stretch for 16-26 CPC

There is no linear correlation between fabric recovery and temperature/density(CPC) set on machine (see Table 14). However, it is found that when the density is keptaround 20 $\mathrm{CPC}$, it willresult in relatively high and balanced recovery (82.95\% and $83.65 \%$ for weft and warp direction,respectively). The higher elongation does not associate with higher elastic recovery. In Figure7, the fabric with $16 \mathrm{CPC}$ shows highest elongation, but in Figure 8, it demonstrates the lowe stelastic recovery due to its loose structure.

\section{The effect of heat setting on elongation under $100 \mathrm{~N}$}

The heat setting process like heat setting duration time and temperature is an important factor toinfluence the elastic property. In this study, 4 levels of temperature were applied at $145^{\circ} \mathrm{C}, 155^{\circ} \mathrm{C}, 165^{\circ} \mathrm{C}$ and $175^{\circ} \mathrm{C}$ for each heat setting time. In addition to this, 3 levels of heat setting duration time wereapplied at $40 \mathrm{~s}, 45 \mathrm{~s}$ and 50 s for each temperature. . Before heat setting, the washed fabric had $128.32 \mathrm{~cm}$ and $115.88 \mathrm{~cm}$ elastic elongation under $100 \mathrm{~N}$ tension.

As shown in Figures 8 (a) and (b), when the fabric was treated at $145^{\circ} \mathrm{C}$, the elongation under $100 \mathrm{~N}$ had the highest values among 4 levels of temperature, whatever was the duration time selected for both weft and warp directions. It was also observed that when the duration time increased from 40 sto $50 \mathrm{~s}$, the elongation under $100 \mathrm{~N}$ at weft and warp directions had an inclined trend expect the weft direction at $145^{\circ}$. It is proved that the long heat setting duration will damage the elasticity of PBT filament. In general, fabric treated at $145^{\circ}$ at 40 s and $45 \mathrm{~s}$ had better balanced elongation at weftand warp directions Elongation $_{\text {weft }}=106.22 \mathrm{~cm}$, Elongation ${ }_{\text {warp }}=123.66 \mathrm{~cm}$ at $40 \mathrm{~s}$; Elongation $_{\text {weft }}=102.32 \mathrm{~cm}$, Elongation warp $^{=}=128.25 \mathrm{~cm}$ at $45 \mathrm{~s}$ ).

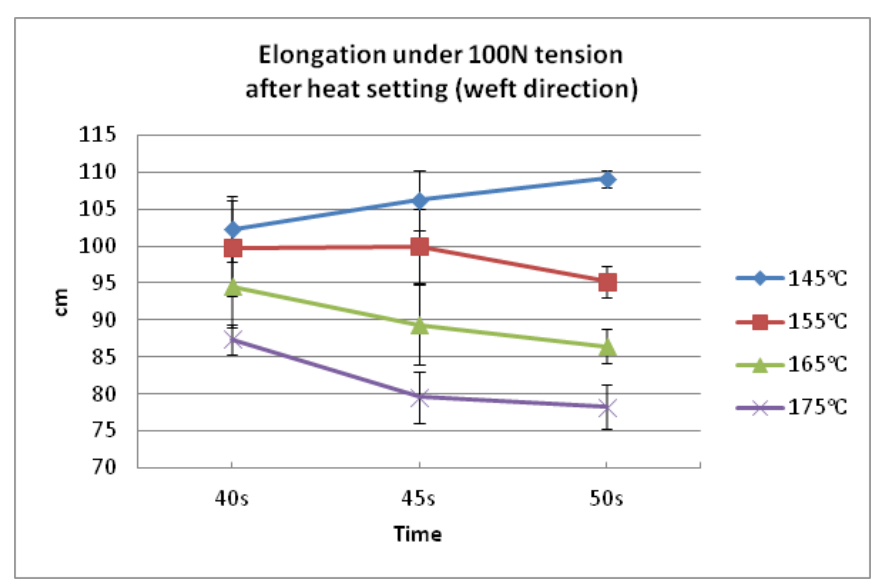

(a)

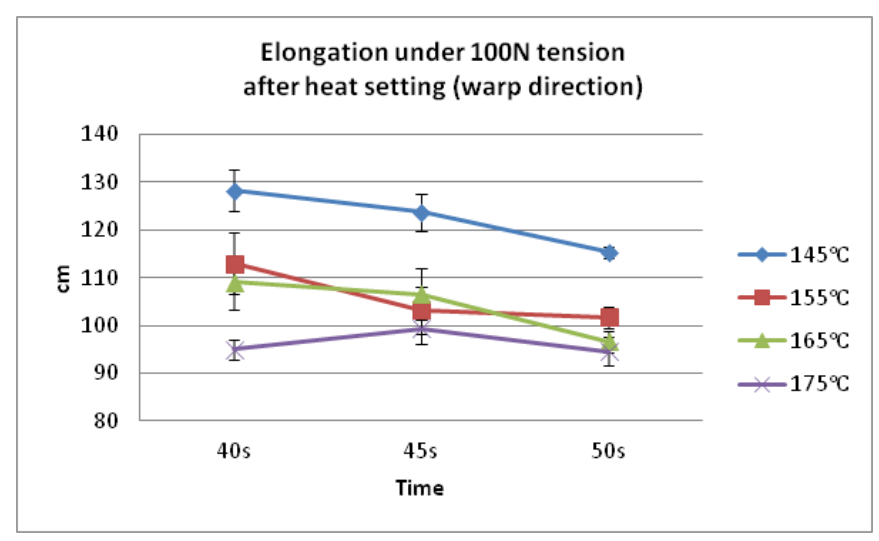

(b)

Figure 8. The elongation under different heat setting temperature and duration time

For fabric after hot water wash, the weft elongation was larger than warp elongation. And for dyedfabric, it wasthe same observation. However, after heat setting, the weft elongation was smaller than the warp elongation. It might be that during heat setting, there wasexternal tension to stretch the fabric

Table 14. The relationship between the recovery and dyeing and density on machine

\begin{tabular}{|c|c|c|c|}
\hline & Regression equation & $\mathbf{R}^{2}$ & significance \\
\hline$Y_{1}$ :recovery in weft direction & $Y_{1}=-0.322 X 1-0.290 X 2+124.077$ & 0.150 & 0.297 \\
\hline$Y_{2}$ :recovery in warp direction & $Y_{2}=-0.311 X 1-0.2 X 2+111.824$ & 0.203 & 0.182 \\
\hline
\end{tabular}

$X_{1}$-density; $X_{2}$-temperature 
width slightly. It was concluded that any stretch at heat setting process will destroy the elastic elongation of PBT fabric.

The relationship between elongation and temperature and duration time was analyzed (see Table 15). High temperature and long duration time of heat setting significantly diminished theelongation of PET/PBT fabrics to different extent due to high $R^{2}$ values $\left(R_{\text {weft direction }}^{2}=0.915, P<0.000 ; R_{2 \text { warp direction }}=0.844\right.$, $\mathrm{P}<0.000$ )

\section{The elastic recovery property of final finished fabrics}

The elastic property not only includes the elongation at certain tension but also elasticrecovery, which determines the dimensional stability of elastic garment. Hence, the PET/PBT warpknitted fabric was examined in terms of elastic recovery after repeated stretch at different extension ratios. After the fabric was dyed in $130^{\circ} \mathrm{C}$ for $30 \mathrm{~min}$, and heat setting at $145^{\circ} \mathrm{C}$ for $40 \mathrm{~s}$, the finished fabric was tested to examine the elastic recovery. The elongation under $100 \mathrm{~N}$ of thisfabric is $142.63 \mathrm{~cm}$ at weft direction and $108.28 \mathrm{~cm}$ at warp direction.

Figures 9 (a) and (b) indicate that the elastic recovery at 1 cycle was higher than 3 and 5 cycle srepeated stretch generally. That is because the fabric was stretched at low cycle, which affects theelastic recovery at limited extent. But when 3 and 5 cycles were compared, the 5 cycles at $10 \%, 30 \%$ and $50 \%$ extension had higher recovery than 3 cycles at weft direction, and similar at warp direction.

For 3 cycles and 5 cycles, the recovery at $30 \%$ extension was highest among three extension levels.It was found in Mani's study[21] that recovery increased from $20 \%$ to $30 \%$ extension after 10 cycles stretch, while it decreased from $40 \%$ and $50 \%$ in both weft andwarp direction. Fabric extension from $10 \%$ to $30 \%$ may cause only loop deformation, which maynot affect the residual energy of the spandex.[21] But the fabric at extensions from $30 \%$ to $50 \%$ resulted in yarn stretch from its loop structure and at this extension level, the spandex in thefabrics reduced its residual energy.[21]

However, there is no such finding for 1 cycle extension. It might be for 1 time extension; the tension only stretched the loop structure into initial balanced stage. During normal wear, thegarment will be stretched for more than 1 cycle. The value of recovery after repeated stretch is more important. The highest recovery is $83.39 \%$ for weft direction and $79.35 \%$ for warp direction at $30 \%$ extension for 5 cycles stretch.

Figures 10 (a) and (b) show the final elongation after 1,3 and 5 cycles stretch at $10 \%, 30 \%$ and $50 \%$ extension. For weft direction, the shortest value $(112.3 \mathrm{~cm})$ was observed at $30 \%$ extension for 5 cycles stretch. For warp direction, the shortest value $(103.7 \mathrm{~cm})$ also was found at $30 \%$ extension but for 1 cycle stretch. 3 cycles stretch had the highest values both in weft and warp directions, no matter at what extension. Although the recoveries at weft and warp directions weresimilar, the final elongation at weft direction after repeated test was higher than that at warpdirection.

\section{Stress at Specific Extension}

Analysis of stress imposed for the applied extension is important to study the pressure between the body and garment. The higher the stress value, the higher the skin strain. The stress values of the fabrics for applied extension levels are given in Figure11.

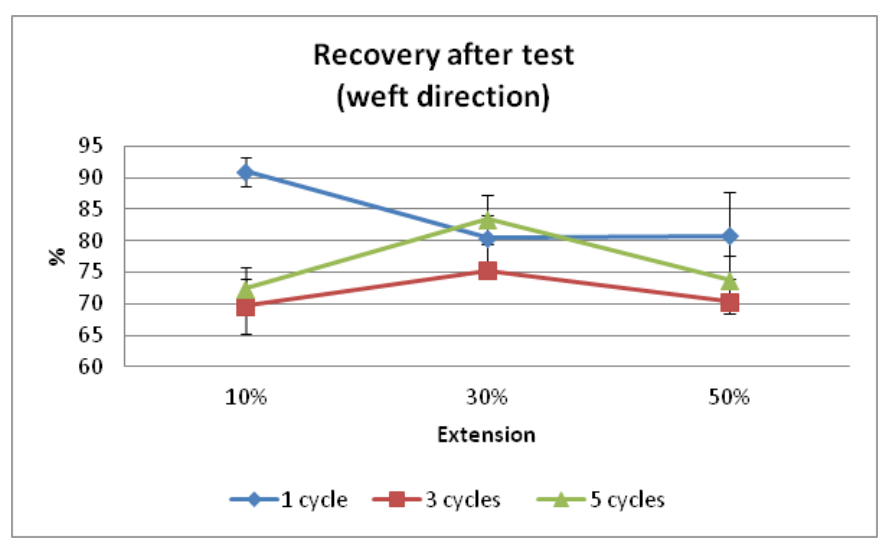

(a)

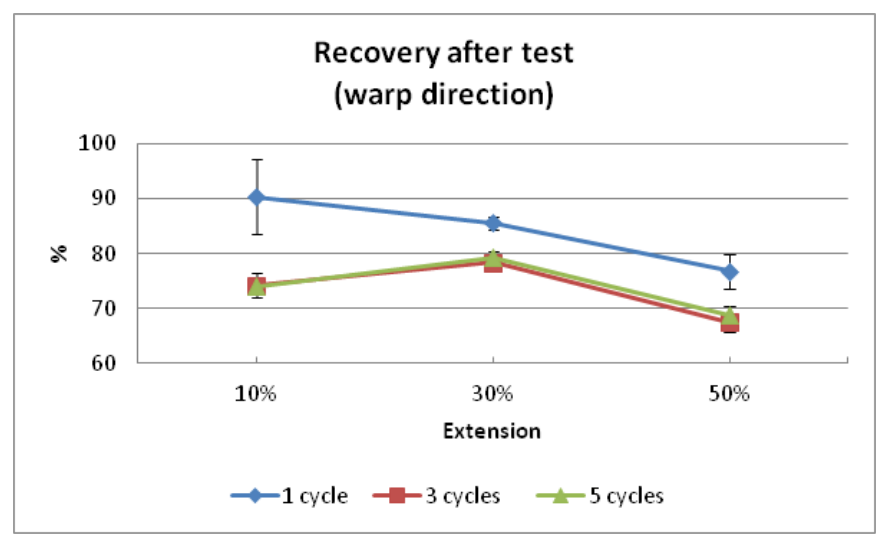

(b)

Figure 9. The elastic recovery after recovery test under $10 \%, 30 \%$ and $50 \%$ for 1,3 and 5 cycles

Table 15. The relationship between the elongation and heat setting temperature and duration time

\begin{tabular}{|c|c|c|c|}
\hline & Regression equation & $R^{2}$ & significance \\
\hline$Y_{1}:$ elongation in weft direction & $Y_{1}=-0.376 X 1-0.807 X 2+239.99$ & 0.915 & 0.000 \\
\hline$Y_{2}:$ elongation in warp direction & $Y_{2}=-0.923 X 1-0.803 X 2+111.824$ & 0.844 & 0.000 \\
\hline$X_{1}-$ duration time $; X_{2}-$ temperature &
\end{tabular}


In general, the fabric stress values for applied extensions in warp direction are higher than that ofstress values in weft direction. At $10 \%$ extension, the $1 \mathrm{~N}$ should be applied to stretch the fabric.At $30 \%$ stretch, $3.5 \mathrm{~N}$ should be applied at weft direction, $8 \mathrm{~N}$ at warp direction. At $50 \%$ extension, $13 \mathrm{~N}$ and 29 Nshould be loaded on the fabric.

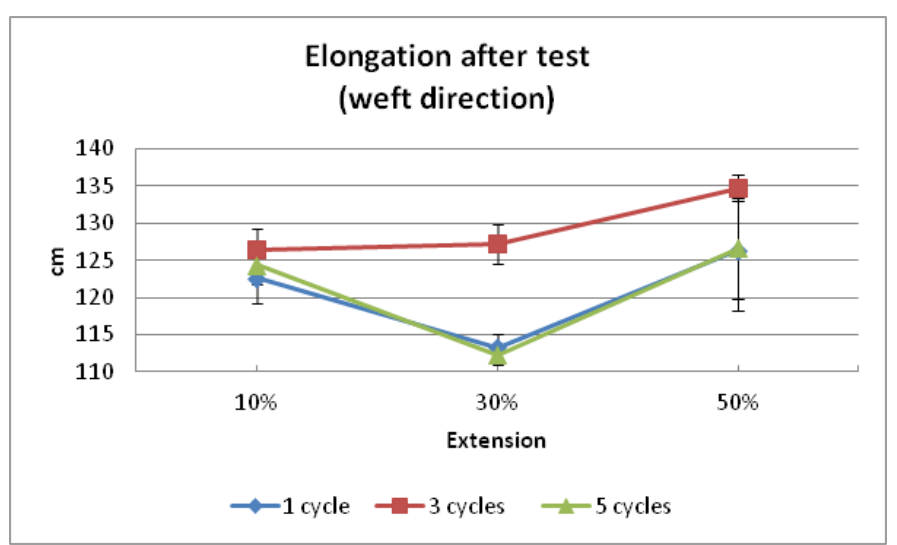

(a)

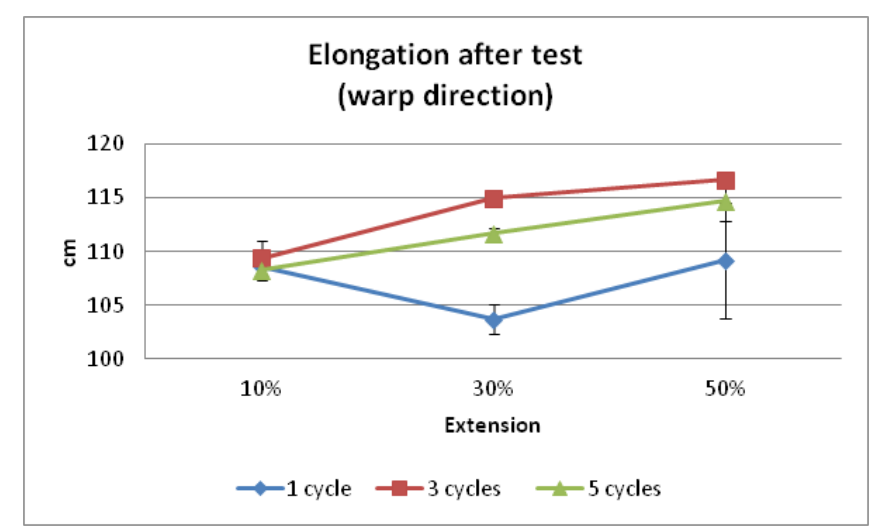

(b)

Figure 10. The elastic elongation after recovery test under $10 \%, 30 \%$ and $50 \%$ for 1,3 and 5 cycles

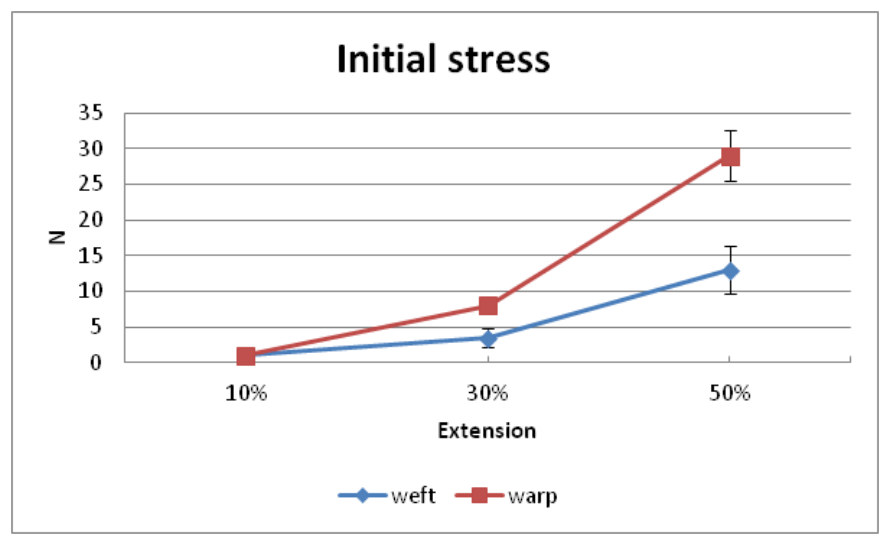

Figure 11. The stress values of the fabrics for applied extension levels

\section{Conclusions}

Elastic knitted fabrics were widely used in active sportswear due to their stretch property. PET/PBTwarp knitted fabric had $100 \%$ chlorine resistance when compared with spandex fabrics. In order to achieve the desirable stretch, this paper investigates the effect of knitting parameter on the elastic elongation of warp knitted fabric. Besides, the dyeing temperature, heat setting temperature and heat setting duration time was studied to achieve better elastic elongation and recovery. The high shrinkage effect of the filament should be taken into consideration at the knitting stage to make sure that the finished product has the correct size and weight. These results provide a better understanding of the characteristics of PET/ PBT warp knitted fabric, and its elastic elongation and recovery behavior for development and effective applications.

Further study should be conducted to examine other wearing properties, such as heat and moisture comfort, pressure comfort and fabric physical property for different end usage. It is needed to extend the investigation to garment pressure on human body, as well as to analyze the deformation of human body under the balanced biaxial stretchability, which simulates the real application state of elastic knitted fabric pressure and compression.

\section{Acknowledgement}

This work was supported by the National Science Foundation of China under Grand 51403080and 11302085; Natural Science Foundation of Jiangsu Province of China under GrandBK20140161; Fundamental Research Funds for the Central Universities of China underJUSRP11448; Innovation fund project of Cooperation among Industries, Universities \& Researchlnstitutes of Jiangsu Province of China under BY2014023-34 and BY2014023-20.

\section{Reference}

[1] Verdu, P., Rego, Jose M., Nieto, J., Blanes, M. Comfort Analysis of WovenCotton/Polyester Fabrics Modified with a New Elastic Fiber, Part 1 Preliminary Analysis ofComfort and Mechanical Properties. TEXT RES J. 2009; 79 (1):1423.

[2] Chattopadhyay, R., Gupta, D., Bera, M. Effect of input tension of inlay yarn on thecharacteristics of knitted circular stretch fabrics and pressure generation J TEXT INST,2012; 103(6): 636-642.

[3] Serkan, T., Yasemin. K. Experimental Investigation of Effects of Spandex Brand andTightness Factor on Dimensional and Physical Properties of Cotton/Spandex Single JerseyFabrics. TEXT RES J, 2008; 78(11): 966976.

[4] Zhou, J., Li, Y., Lam, J., Cao X. The Poisson Ratio and Modulus of Elastic KnittedFabrics, TEXT RES J, 2010; 80(18): 1965-1969.

[5] Wang, Y., Zhang, P., Zhang, Y. Experimental investigation the dynamic pressureattenuation of elastic fabric for compression garment. TEXT RES J, 2014; 84(6): 572582.

[6] Zhao, L., Hu, H., Shen J., Rong, H. The use of a polytrimethyleneterephthalate/polyester bi-component filament for the development of seamless garments, TEXT RES J, 2013; 83(12): 1283-1296.

[7] Gokarneshan, N., Thangamani, K. An investigation into the properties ofcotton/spandex and polyester/spandex knitted fabrics. J TEXT INST,2010; 101(2):182-186. 
[8] Bera, M., Chattopadhay, R., Gupta, D. Effect of linear density of inlay yarns on thestructural characteristics of knitted fabric tube and pressure generation on cylinder. $J$ TEXT INST,2015; 106(1):39-46.

[9] Manshahia, M.,Das, A., (2014) Thermophysiological comfort characteristics of plated knitted fabrics. J TEXT INST.2014; 105 (5): 509-519.

[10] Das, A., Chakraborty, R. Studies on elastane-cotton corespun stretch yarns andfabrics: Part II - Fabric low-stress mechanical characteristics, . INDIAN J FIBRE TEXT, 2013; 38(4): 340-348

[11] Manshahia, M., Das, A. Thermo-physiological comfort of compression athletic wear.INDIAN J FIBRE TEXT, 2014; 39(2): 139-146.

[12] Onofrei, E., Rocha, A. M., Catarino, A. Investigating the effect of moisture onthe thermal comfort properties of functional elastic fabrics, J IND TEXT, 2012; 42(1): 34-51.

[13]Senthilkumar, M., Anbumani, N., Hayavadana, J. Elastane fabrics - A tool for stretch applications in sports, INDIAN J FIBRE TEXT, 2011; 36(3): 300-307

[14] Senthilkumar, M.., Anbumani, N.Dynamics of Elastic Knitted Fabrics for SportsWear. J IND TEXT, 2011; 41(1):13-24.

[15] Herath, C. N., Kang, B. C. Flexural Stiffness of Core Spun Cotton/Spandex WeftKnitted Structures Under Relaxation and Machine Washing Treatments. FIBER POLYM, 2012; 13(10): 1341-1347.
[16] Herath, C. N. Investigation of Air Permeability of Core Spun Cotton/Spandex WeftKnitted Structures Under Relaxation, FIBER POLYM, 2013; 14 (8):1339-1346.

[17] Kumar, V.; Sampath, V. R. Investigation on the Physical and Dimensional Propertiesof Single Jersey Fabrics made from Cotton Sheath - Elastomeric Core Spun. FIBRES TEXT EAST EUR, 2013; 21(3): 73-75,

[18] Cuden, A. P., Hladnik, A., Sluga, F., Impact of material, structure and relaxationprocess parameters of elasticized single-knitted fabrics on loop length.TEXT RES J,2013;83(1): 56-65.

[19] Ucar, N., Karakas, H., Sen, S. Physical and comfort properties of the hosiery knitproduct containing intermingled nylon elastomeric yarn, FIBER POLYM, 2007; 8(5): 558563.

[20] Lee, CG. Changes of pulling-out length and shrinkage ratio in polyester/spandexpower net warp knitted fabrics. FIBER POLYM, 2006; 7(1): 51-56

[21] Mani, S., Anbumani, N. Dynamic Elastic Behavior of Cotton and Cotton/Spandex Knitted Fabrics, J ENG FIBER FABR, 2014; 9(1): 93-100.

[22] Voyce, J., Dafniotis, P., Towlson, S. "Elastic Textiles, Textiles in Sport", Wood HeadPublications, Cambridge, UK. 2005. 